\title{
ONLINE LEARNING: NEW MODELS FOR LEADERSHIP AND ORGANIZATION IN HIGHER EDUCATION
}

\author{
George Otte \\ City University of New York
}

Meg Benke

Empire State College

\begin{abstract}
Online learning is now reaching the core, helping to transform higher education and moving beyond isolated efforts to pervasive influence and change. The dichotomy of distance learning vs. campus-based education has broken down, and forward-looking senior administrators have embraced new approaches to education that contain the elements of successful online education while cultivating the communitybuilding and branding of site-based education, particularly to promote enriched faculty and program development. Rather than being isolated in a distance learning task force or continuing education program, the conversations about online learning now occur-or need to occur-at the executive level and throughout other levels and structures.
\end{abstract}

\section{KEYWORDS}

Institutional Transformation, Leadership, Strategic Planning, Community, Scalability

\section{LEADERSHIP: TRENDS AND NEEDS}

Because of growth and scale, things that once could have happened under the radar have begun to attract the notice of senior administration. The need for top-level leadership is, in other words, a function of the progress and growth of online instruction. Online education can't be ignored any longer. If it has taken root, it needs top-level attention to making progress on a broad scale.

Innovation in early stages can be scattershot and highly localized, and so it tends to be centrifugal in effect. However, generalizing innovative practices across an institution and reaping institutional benefits is necessarily centripetal and systematizing. Generalizing innovation must be done carefully and strategically to guide rather than quash innovation.

Work and leadership in innovation must be seen as multi-level. At the top are high-level executive sponsors who have little to do with implementation but may be critical in green-lighting a strategic approach to online instruction; middle management is critical for mobilizing faculty and support; faculty actually do online instruction; and department chairs or program heads either bless or obstruct their involvement in it. Given the need for players at every level, leadership is much more about orchestrating the interaction of all the stakeholders than providing direction in a top-down manner. 
One of the discoveries leadership has made in working with online instruction (a discovery sometimes made the hard way) is just how vital support systems are. Increasingly, support systems for all students have been built on successful strategies for reaching out to distance students. But service models in many campuses still focus predominantly on campus-based students, typically a matter of making the student come to the service instead of the other way around. As online services reach (and perhaps become) the mainstream, resources need to be shifted to improve services for all students rather than compartmentalizing services. In some ways, as leaders must recognize, the providing of services online, even more than the delivery of courses online, needs to be brought into core operations. A coherent support structure is essential.

\section{LEADERSHIP IN ONLINE PROGRAMS: MULTIPLE ROLES/TASKS}

Because the principal change agents are those managing new modes of delivery-and brokering the meshing of the old and the new-the pivotal leadership comes from them, dependent as they are on those above and below, on executive sponsorship and on the full cooperation of support staff and engaged faculty. Such leadership is a matter of bridgework as well as trailblazing, and the people who carry it out need to be aware of complex tasks and multiple roles.

\section{A. Advocacy and Integration}

Getting colleagues to adopt and adapt is vital. It involves making what is new familiar without shortcircuiting its transformative value. Although they sometimes began as separate or satellite enterprises, online programs need their own integrity; for full growth and impact they also need integration with the larger academic enterprise. Therefore, advocacy of online instruction-a new means of instructional delivery and interaction-is also a means of practicing sound pedagogy, upholding quality by accomplishing longstanding goals and the general mission, This delicate relationship to the status quochanging the student constituency even while serving it, for instance-is critical.

\section{B. Academic and Curricular Leadership}

One thing that makes leadership in online instruction especially complicated is that it does in fact entail academic and curricular leadership. Pedagogical advances tend to be concentrated in online instruction, and they are more easily shared once made; the growth in collaborative work, active inquiry, and so on has much to do with the development and visibility of such practices in online instruction.

Sharing can of course make faculty not engaged in such work feel threatened. And it really isn't enough to placate them with assurances that online instruction is basically old wine in new bottles, because that isn't the case. Teaching online is not merely using a different medium; the medium itself has a transformative effect. At the same time, there has to be an insistence that courses offered online are commensurate with traditional, on-the-ground courses: they must meet the same goals and satisfy the same requirements. Walking this tightrope between what is genuinely new and different and what is nevertheless commensurate with established practice is a special challenge to leadership in this area.

\section{Program Building and Change Management}

Much of standard academic enterprise is predicated on maintaining what is in place: ensuring ongoing instructional delivery, quality, and support. Online instruction is a growth area that can never simply maintain, but must perpetually grow and develop. Partly, online instruction is a response to demand 
Online Learning: New Models for Leadership and Organization in Higher Education

(always outpacing supply), and partly, it is a fact of technological change (which never stands still). What's more, the two are connected: technological change is not just change, but improvement: systems become more stable and scalable, while their integration with other systems (such as student information management, registration, and more) becomes both possible and even necessary. Even a start-up plan has to envision long-term growth, and an established program can never rest on its laurels but must always be ramping up to new levels of growth and outreach.

\section{Liaising with Information Technology}

Teaching with technology means working with technologists. In the university setting, many if not most of the technologists came in to serve administrative rather than academic purposes, and the divide is sometimes described in terms of "two sides of the house." Technology support on the academic side has to be more flexible and less mechanized (or systemic), more adaptable and responsive. When it comes to working with users, leadership in online instruction often is forced into the breach, becoming a buffer between the two sides even as the division between them blurs. After all, it is becoming increasingly difficult to draw the line where one kind of IT (Information Technology) stops and the other (Instructional Technology) begins. Course management systems interface with student information systems and other college administrative systems. Creating systems that are useful to both on-campus and off-campus faculty and students sometimes leads to duplication or confusion. An integrated system allows for greater use and performance by faculty and others, but at times threatens data security. These are important questions as the campus extends beyond its walls.

\section{E. Faculty Development}

Faculty development may be the single most central piece of any program and the single greatest leadership challenge. The Sloan surveys [1] have indicated that faculty buy-in is the great bottleneck, but then faculty sit precisely where workload concerns are concentrated and where the perceived threat posed by online instruction seems greatest. Such concerns cannot be waved away or addressed by mere training in the technology. Any change in instruction is, perforce, a matter of pedagogy, and that is never adequately addressed by a recipe-like how-to approach.

The challenge is exacerbated in institutions of higher education, since, unlike $\mathrm{K}-12$ instruction, colleges and universities really don't have a culture of professional development. Its presence is typically a localized and temporary thing that is often compared to setting up the evangelical tent and attempting conversions-something that almost never lasts, partly because the grant money that makes it possible can't last either. Faculty development is such a leadership challenge because it must be done with and (not just to) faculty. Faculty must take ownership of the methods and models and must share in leadership.

The challenge for effective faculty development is considerable, and rising to it has what is arguably the greatest pay-off, the greatest shot at institutional and cultural transformation. Precisely because it is so critical to effective online learning, and is so sporadically manifest elsewhere in academic culture, faculty development for online learning is poised to become the focus of faculty development and pedagogical transformation in institutions of higher education generally. Often Centers for Teaching with Technology become Centers of Teaching and the change is not just nomenclatural. Effective faculty development for online learning is another transformative element that needs to move from the margins to the core.

Faculty and faculty development are also changing as new generations of faculty appear. Emerging generations of faculty will influence existing faculty and development models. Online interaction with 
students as a daily activity can mean that managing an online discussion does not seem like a chore, but this requires a cultural shift from concentrating teaching in blocks of time to distributing it across the entire week. Mitigating factors such as the reward and tenure system predicated primarily on publications may act as a brake on creativity and development in areas dedicated to "teaching," but such factors are also susceptible to reform; they may even, ultimately, act as accelerators rather than brakes if properly devised. Of course, this depends upon the institutional mission, which must itself evolve.

\section{ORGANIZATIONAL MODELS FOR CHANGE - THE POSSIBILITY OF CONVERGENCE}

What are the appropriate organizational models? So much is contingent on where the institution is, what purposes online instruction is supposed to serve, and more. But the growth of online learning, its rhizomelike reach into all aspects of institutions of higher education, poses the intriguing possibility that we are converging on a single, integrative model, albeit from different directions.

\section{A. Outward-reaching vs. Inward-focused}

It would certainly be possible to develop a much more complex typology, but outward-reaching vs. inward-focused were the chief points of departure for organizational models:

- Programs that were started primarily as separate programs for outreach to bring in new or specific student populations, or

- Programs that were started to take advantage of tech-mediated delivery for existing populations, sometimes more through blended learning than fully online learning.

Interestingly, there is some indication that the two are converging-that the programs that began as separate from the mainstream are now merging with it, even "capturing the core," while those that began with a sense that it was time to use $21^{\text {st }}$ century methods on a well-established mainstream and mission are discovering that those methods create possibilities of access for new/expanded as well as traditional student populations.

\section{B. The Institution Itself as a Determinant of Direction}

As convergence occurs, how online education is ultimately organized depends more on the nature of the institution than just how online instruction first took hold within it. We know, for example [1], that public institutions are more likely to have made significant progress with online instruction than private institutions (particularly small liberal arts colleges). The institutional mission that is fundamentally about outreach and service is more congenial to the start and growth of online education than the institution that attracts (usually affluent) students with the promise of small student/faculty ratios and instructional and social intimacy.

Such observations are hardly counter-intuitive. A greater challenge is envisioning how online instruction will itself change institutional mission in the long run. How important will institutional branding become? How important will it be to accommodate cross-institutional enrollments? How much will student populations shift from on-campus to off-campus? How much will students want to mix modes of delivery in putting together their individual academic programs? One especially strong possibility is suggested by two things in particular: (1) the near-ubiquity of online instruction in institutions of higher education, at least as some kind of presence and option, and (2) the remarkable, almost incalculable growth of blended learning: since students may have access to online instruction from local (as well as distant) providers. 
The key element in anytime/anyplace instruction will probably be more a matter of time than distance, scheduling flexibility than sheer access.

Models of change must plan for growth in student populations that had formerly had only a part-time presence or no access at all because of work schedules, parenting responsibilities, and so on. Such growth means growth throughout the institution, not just in enrollments, but in support services of all kinds. It also suggests the need to rethink timeframes of instruction on a much larger scale than heretofore. The rationale for the 14-week term because class could only meet three specified hours a week will be radically undercut. Ultimately, there could be a profound redistribution of resources, teaching staff, and administrative focus that models of change would need to accommodate as foreseen outcomes of projected growth, rather than as unexpected shocks to the system.

\section{Modeling Change Throughout Levels/Units}

Everything said thus far stresses that any organizational model for change is going to be deployed within an organization undergoing change - and so has to foresee and accommodate such change. Some changes are fairly easy to predict - a tendency toward increasing integration, for instance-but what these mean to different units and programs and campuses (in a multi-campus structure) is far less predictable. We are still relatively ignorant of what discipline- or program-specific dispensations may obtain in online instruction. A fairly generic approach to online education may be representative of first-phase implementation rather than an ongoing condition. In a multi-campus system, similar programs may be consolidated, but they may also present a welcome redundancy for students for whom scheduling flexibility is the chief desideratum. Such questions have to be worked out at all levels: they pose clear challenges for everyone from senior administrator to department head, and these challenges further suggest that the leadership of online instruction specifically will have to broker the confrontation of such challenges.

\section{How Academic Uses of Technology Get Defined and Supported}

Treated to some extent already (see the leadership role "Liaising with IT"), the issue of technology support is actually a still larger issue brought to the fore by the fact that tech-mediated instruction is still more pervasive than online instruction. Competing claims to technology on the academic side need to be sorted out- "smart" classrooms vs. "virtual" ones, high-tech hands-on science labs vs. online simulations, and so on. The best way to sort out competing claims while taking the long view may in fact be to "flip the script." Instead of asking, as formerly, what purpose online education is to serve, it may be time to ask what special needs and purposes of campus-based education can be expected to persist.

\section{E. The Bridging Function of Online Education}

The positive side to the challenges we've been outlining is that they all speak to the way online instruction is increasingly the fulcrum of an institution's future. The ubiquity of tech-mediated teachingits tendency to pervade and so to bring together all aspects of an institution of higher education, to reach throughout the curriculum, to make demands on every aspect of resource management-makes it the logical place to weave together the new and the old, the academic and the administrative, the technological and the traditional. Like the technology it uses, online instruction has an integrative function in the compartmentalized universe that is the university. In a multi-campus institution, for instance, its capacity to foster cross-campus enrollments can help knit disparate units together, while its focus on faculty development can give pedagogy an attention that transcends disparate departments, even kinds and levels of instruction. 


\section{F. The Need to Bring All the Stakeholders In}

Easy to say, hard to do. The key thing may be that, in an institutional setting, due consultation rarely takes the form of a general plebiscite. The obligation to engage in due consultation is more a matter of communication than a referendum. The one imperative is always forward mobility: inertia cannot triumph in the face of a need for a change management decision, but a decision cannot be so preemptory as to harden resistance or invite stonewalling (the one thing that is, from a change management perspective, even worse than inertia).

\section{G. The Critical Need to Engage in Strategic Planning}

Strategic planning once meant a master plan, then the follow-through, an exercise that was about as cyclical and sporadic as accreditation self-study. Now strategic planning is (or at least needs to be) an ongoing process of revolution by evolution. Minimally, plans need to be done annually, but always with a long-term dimension over the next 3-5 years. Ideally, the committees that prepare strategic plans have to be on-going and comprehensive, representing all the interests: administration, tech staff, faculty, students.

Ultimately, institutions need to break from the old model of strategic planning to a formal, continuous improvement cycle. For one thing, strategic plans tend to be focused on units-separate documents for separate endeavors - and institutions need to plan strategically in ways that are broader, more integrative, and more continuous. The advent of new or significantly changed technologies-portals, ERP, broadband, wireless networking, blogs, wikis, and more-changes the nature of the game. These things become features of the landscape, though not always in ways originally envisioned or intended. Being able to respond to such changes requires that planning is not an event but a perpetual process. There needs to be a body that monitors trends as well as institutional implementations, a group as broadly representative as possible and as pro-active (as opposed to reactive) to such change as possible.

\section{H. New Models for Faculty}

For the sake of efficiency (and, from students' perspectives on accessibility and navigability) there probably needs to be some uniformity in the delivery of online instruction. How this is achieved (e.g., by course management systems or instructional design teams) will vary, but certain principles need to be operative. First among these is probably the effective integration of technology in teaching, or, as another way of putting this, a wariness about anything that distances the faculty from issues of delivery that are (or have impact on) important pedagogical choices. Instruction that is egregiously uniform (templatedriven) is probably suspect; similarly, the so-called "disaggregation of the teaching function" (the breaking of the teacher's role into a variety of roles, from "master" teacher to discussion leader, from examiner to grader, from course planner to instructional designer or "course builder") has been touted as a cost-efficient means of improving "faculty productivity," but such approaches have their downsides, and there needs to be careful planning and assessment of such ventures. In the largest and longest view, the balance that needs to be struck here is part of a large balancing act between centralization and decentralization, uniformity and diversity, stability and innovation.

\section{CENTRALIZATION VS. DECENTRALIZATION}

What processes should be centralized or decentralized for most effective implementation and organization of online learning at an institution or within a system? How should work and funds flow be rationalized? 
The question of centralization vs. decentralization can be reframed as that of consolidation vs. differentiation. Consolidation maximizes efficiency and control, whereas differentiation heightens innovation and a sense of local ownership. The ideal situation is probably one in which matters of resource management are centralized, while the means and methods of instruction those resources make possible are largely controlled by those doing the teaching.

But because such situations are never static, even such an ideal situation must accommodate negotiation and change. If, for example, there is a common course management system, faculty using it must feel they have input and flexibility. And even if faculty have some control over the delivery of instruction, there must also be a way of regularizing its delivery so that centrifugal forces don't take over.

Particularly in some of the larger regional or state systems there has been outsourcing of some major aspects of programs such as course platforms, servers, and help desk support to either a commercial provider or a centralized unit. This consolidation does maximize some efficiency and allows for shared investment in improvements. It does at times lead to challenges when faculty have high stakes in the look and feel of a course management system once they get comfortable. High-end technology faculty also are interested in innovative uses of technology, when the more consolidated systems sometimes lack agility and responsiveness. (We need to acknowledge that it is not just that technology is changing teaching: teaching keeps pushing and changing the technology.)

\section{A. Mapping Patterns and Directions}

Given the dynamic forces, what an institution really needs is not a model but a mapping of where and how things are moving. So much of that has to begin with where things were focused initially (growth and outreach vs. "capturing the core”).

Even if we agree that there is an ideal balance, that is never where and how things begin, and the one great question for change management is how to direct the way things are toward where they should be. Programs that begin as independent operations need to move from satellite status to roles that are increasingly integral; diffuse experiments by faculty need to be corralled, especially for the sake of disseminating such experiments. A program that began as an administrative mandate has to secure faculty buy-in; one that began as a faculty-led initiative needs administrative backing and support. In each case, the movement toward a balance of consolidation and differentiation must not lose its benefits as it seeks to extend them.

\section{B. Bottom-up, Top-down, or Both}

Neither bottom-up or top-down approaches could be prosecuted exclusively, even if that were desirable. Because advantages and disadvantages inhere in both approaches-bottom-up tends to be more centrifugal but innovative, top-down more centripetal in effect but also more generic, more homogenizing - leadership needs to find a way of avoiding the disadvantages while securing the benefits.

To maximize benefits, it is critical to manage the timing and not just the direction of change. A grassroots approach to online education quickly assumes the character of "random acts of innovation" if such work is not brought into larger focus and purpose, and this needs to happen so that it seems a facilitation of such work rather than a reining in. Similarly, an administrative initiative cannot begin too soon to cultivate faculty support and to solicit faculty consultation. 


\section{Ideal Distribution}

Though the possibilities and choices are richer in a "both/and" than in an "either/or" universe, it is important to have clear, goal-directed management. A goal need not be a destination; it can be a waystation. And in an institution with both bottom-up and top-down impulses and effects, the way to travel is clear: the dynamic should settle into issues of ownership (local) and support (general) - the direction is the diffusion of innovation but efficiencies/synergies of central support.

There is no more powerful disincentive than the sense that online instruction is an external imposition and a threat to the faculty prerogatives, but there is no surer way to scuttle a program than to have breaks in the chain of resource management. Faculty engagement tends to flow to programs where pedagogical ownership is at the level of the teacher and the discipline, but support is consolidated and consistent throughout the institution.

\section{QUESTIONS FOR FURTHER DISCUSSION}

Higher education institutions are examining the interfaces between online and blended learning, profitcenters and centralized programs, part- and full-time faculty, and even exchanges beyond departments and institutional boundaries. How do institutional leaders at each level consider the most effective program design issues and implement institutional change? Executive sponsors may encourage strategic approaches to online instruction, but middle management must mobilize resources and department chairs in most institutions must approve. Do "normal procedures" allow for transformation?

Do higher-level administrators know enough about online and tech-mediated instruction? Do we need a kind of administrative development as well as faculty development? If so, how might that be pursued?

Is higher education converging on an integrated model for online learning, even though we have come from many different places of origin for online learning?

We have framed issues of consolidation versus differentiation. In the ideal, should resource and information technology management be centralized to maximize efficiency and the means and methods of instruction, which use those resources, be decentralized to promote differentiation? Do models based on cost recovery work?

Has online education had real impact on the core of our higher education institutions? Have we focused on what drives us, and where we can excel [2]? At the leadership level, have we transformed with core administrative and student services functions?

What are the impact of online education and higher level discussions of faculty roles? How will or should growth and dissemination affect part-time/full-time ratios, models of faculty development, processes of program approval and faculty governance, tenure and reward structures, and so on?

How is innovation in higher education supported at the local level, but then encouraged to spread?

How good are institutions of higher education at anticipating change so they can respond proactively rather than reactively? 
Do we need to rethink the standard instructional models (term length, contact hours, classroom usage, residence requirements, etc.) more extensively?

How much should change be driven by student preferences, especially those shaped more by convenience than need? Do we know enough about student preferences with regard to the different modes?

\section{REFERENCES}

1. Allen, E. I. and J. Seaman. Sizing the Opportunity: The Quality and Extent of Online Education in the United States, 2001 and 2003. The Sloan Consortium: 2003. Online: http://www.sloanc.org/resources/sizing_opportunity.pdf.

2. Collins, J. Good to Great and the Social Sectors: A Monograph to Accompany Good to Great. Harper Collins, NY: 2005.

\section{ABOUT THE AUTHORS}

George Otte is on the doctoral faculties of the CUNY Graduate Center programs in English, Urban Education, and Technology and Pedagogy. Since March 2001, when he was named Director of Instructional Technology for CUNY, he has been supervising CUNY Online, the City University's faculty/course development program for online instruction, supported by the Sloan Foundation.

Meg Benke is Dean of the Center for Distance Learning of the State University of New York, Empire State College (ESC), with 20,000 online enrollments per year. Empire State was among the first institutions delivering complete online degree programs and now offers all of the College's Areas of Study online. ESC was a founding partner of the SUNY Learning Network, which has been generously funded by the Sloan Foundation. Dr. Benke now also serves as Student Satisfaction Pillar Editor for the Sloan-C Asynchronous Learning Networks. 